\title{
MAKNA ELEMEN PENDUKUNG INTERIOR PADA ARSITEKTUR RUMAH IBADAH
}

\author{
Robertus Krismanto ${ }^{1}$, Rudyanto Soesilo², Bernadeta Tyas Susanti ${ }^{3}$ \\ ${ }^{1}$ Jurusan Desain Interior, Akademi Teknik Pika Semarang \\ Email:25krispika@gmail.com \\ ${ }^{2}$ Fakultas Arsitektur Dan Desain, Universitas Katholik Soegijapranata Semarang \\ Email: rudyanto@unika.ac.id \\ ${ }^{3}$ Fakultas Arsitektur Dan Desain, Universitas Katholik Soegijapranata Semarang \\ Email: santi@unika.ac.id
}

Masuk: 13-05-2020, revisi: 29-07-2020, diterima untuk diterbitkan: 26-08-2020

\begin{abstract}
ABSTRAK
Arsitektur dan interior Gereja Hati Kudus Tuhan Yesus Ganjuran (HKTY) Bantul Yogyakarta berupa joglo dengan elemen pendukung interior berupa furnitur, patung -patung, ragam hias, kubah, lukisan kaca. Penelitian ini menggunakan metode kualitatif dengan studi kasus pada Gereja HKTY Ganjuran fokus penelitian pada menemukan makna elemen pendukung interior. Pengambilan data melalui wawancara, observasi, dokumentasi, dan studi pustaka. Hasil penelitian bahwa elemen pendukung interior mempunyai makna untuk mendukung umat berdoa atau beribadat. Pada beberapa perabot terdapat ornamen tentang burung pelikan yang mempunyai makna Hati KudusYang Maha Kudus, yang bersedia memberikan hidup, bagi anak-anaknya agar tetap hidup. Patung - patung dengan busana Jawa agar umat dekat mudah untuk berdoa dengan Tuhan karena hadir dengan wajah Jawa. Ragam hias pada kubah yang berada di atas panti imam ini terdapat gambar simbol ke empat Injil dan Tritunggal Maha Kudus. Maksudnya ketika Imam melakukan konsekrasi dan menengadah keatas selalu meresapi tentang ke empat Injil suci dan Tritunggal Maha Kudus. Lukisan kaca orang Samaria yang baik hati ini terletak di sisi timur panti imam gereja Ganjuran agar umat Katolik seusai mengikuti perayaan ekaristi siap sedia berbuat bagi siapapun yang membutuhkan, sebab iman tanpa perbuatan adalah mati. Warna - warna yang dipergunakan yaitu warna hijau mempunyai makna kesuburan, pertumbuhan dan menandakan pengharapan. Warna kuning emas bermakna kemuliaan Allah, warna merah menunjukkan kemartiran, pengorbanan dan warna hitam mepunyai makna asal mula dan kesejatihan. Umat ketika berdoa semakin terarah kepada Tuhan karena terbantu oleh arsitektur dan interior gereja yang syarat akan makna.
\end{abstract}

Kata Kunci: Gereja HKTY Ganjuran; Elemen pendukung interior.

\begin{abstract}
The architecture and interior of the Church of the Sacred Heart of the Lord Jesus Ganjuran (HKTY) Bantul Yogyakarta in the form of joglo with supporting elements in the form of interior furniture, statues, decoration, domes, glass paintings. This study uses a qualitative method with a case study at the Church of HKTY Ganjuran research focus on finding the meaning of interior supporting elements. Retrieval of data through interviews, observation, documentation, and literature study. The results of the study that the supporting elements of the interior have meaning to support people praying or worshiping. On some furniture there are ornaments about pelicans that have the meaning of the Sacred Heart, the Most Holy, who is willing to give life, for his children to stay alive. Sculptures in Javanese outfit so that people near are easy to pray with God because they come with Javanese faces. The decoration on the dome above the priest's sanctuary contained symbol images of the four gospels and The Most Holy Trinity. That is, when the Imam consecrated and looked up always always permeated the four holy Gospels and The Most Holy Trinity. This kind Samaritan glass painting is located on the east side of the Ganjuran church priest's home so that Catholics after attending the Eucharist are ready to do for anyone in need, because faith without works is dead. The colors used are green which means fertility, growth and indicates hope. The yellow color of gold means the glory of God, the red color means martyrdom, sacrifice and black has a meaning of origin and harmony. The people when praying are increasingly directed towards God because they are helped by the architecture and interior of the church which is a condition for meaning.
\end{abstract}

Keywords: HKTY Ganjuran Church; interior supporting elements. 


\section{PENDAHULUAN}

Gereja Hati Kudus Tuhan Yesus (HKTY) Ganjuran, Bantul, Yogyakarta, dikenal dengan nama Gereja Ganjuran dibangun kembali dan diresmikan pada 29 Agustus 2009, pasca gempa pada 27 Mei 2006, mengadopsi bangunan tradisional Yogyakarta. Bangunan gereja mempunyai tujuan teologis yang berinkulturasi dengan budaya setempat, namun juga menjadi salah satu usaha pelestarian dan pengembangan desain arsitektur dan interior tradisional Yogyakarta. Elemen pendukung interior gereja yaitu: kursi sedilia, kursi umat, kursi misdinar, tabernakel, altar, meja kredens, patung - patung. Sehubungan dengan desain interior maka elemen pendukung tersebut merupakan sarana penting dalam tata peribadatan gereja Katolik, sehingga elemen pendukung interior tersebut semakin membuat umat fokus dan terarah ketika berdoa maupun mengikuti misa. Secara keseluruhan budaya Jawa lebih kuat di Gereja Ganjuran, namun tidak mengubah nilai ajaran Katolik. Fenomena umat untuk beribadat di gereja Ganjuran begitu banyak dikarenakan gereja yang bernuansa Jawa sesuai dengan masyarakat sekitar, juga di area gereja terdapat tempat untuk berdoa lainnya yaitu Candi HKTY Ganjuran, Kapel Adorasi, dan kondisi lingkungan gereja yang mendukung untuk berdoa.

Ornamen - ornamen yang dipergunakan merupakan ornament hias yang berkembang di daerah Jawa, dan sebenarnya sudah bercampur dengan budaya lain yang telah ada sebelumnya, seperti budaya Islam, dan Budaya Hindu-Budha. Ornamen yang dipergunakan pada Gereja Katolik Ganjuran, memiliki makna yang selaras dengan ajaran Katolik walaupun kehadirannya sebagian besar hanya sebagai dekorasi. Beberapa simbol budaya Jawa yang maknanya secara umum dihubungkan dengan ajaran Katolik (Pinasthika, 2011).

Keluarga Schmutzer membuat Candi Ganjuran sebagai hasil dari pergulatannya dalam membela pribumi Jawa. Candi itu menjadi simbol perlawanan terhadap penjajah. Schmutzer menghadirkan kekristenan sebagai agama baru dalam wujud sesuai budaya Jawa. Akulturasi yang dilakukan tidak ditanggapi oleh umat Katolik di Ganjuran karena merasa asing dengan tempat ibadat yang berbentuk candi sehingga terabaikan selama enam puluh tahun. Situasi tersebut ditanggapi oleh Rm. Gregorius Utomo selaku pastur paroki HKTY dengan membuat Gerakan yang berakar dari gagasan Schmutzer yaitu terkait dengan kesejahteraan rakyat dan spiritual. Gerakan ini membawa perubahan sosial yang cukup besar, yaitu Candi Ganjuran menjadi tempat ziarah yang ramai dikunjungi. Rm. Gregorius Utomo juga sebagai salah satu tokoh yang memprakarsai gereja HKTY Ganjuran dengan wujud gereja yang berinkulturasi dengan arsitektur Jawa (Bramasti, 2015). Makna simbolis dekorasi di dalam gereja HKTY Ganjuran terdapat pada ukiran yang didominasi oleh tumbuhan yang merupakan simbol kehidupan, ukiran anggur dan tangkai gandum simbol Tubuh dan Darah Kristus, ukiran burung merpati dan lidah api yang menyimbolkan roh kudus (Kurnianto, 2016). Ini selaras dengan penelitian (Cahyo Nugroho, 2016), bahwa unsur - unsur gereja HKTY Ganjuran dihadirkan melalui penambahan -penambahan ornamen dengan simbol-simbol liturgi budaya Jawa, yang memiliki makna selaras dengan ajaran Katolik, walau hadirnyas sebagai dekorasi.

Hasil salah satu kesimpulan tesis (Sitinjak, 2011), pada beberapa bagian interior gereja memiliki kemiripan dengan interior Ruma Batak Toba, tapi secara menyeluruh elemen - elemen interiornya menunjukkan identitas interior sebuah gereja Katolik, daripada interior bangunan tradisional Ruma Batak Toba.

Istilah inkulturasi dipergunakan pertama kali dalam dokumen resmi gereja pada tahun 1977, ketika sinode para uskup Gereja mengenai katekese, yang mengeluarkan naskah terakhir "pesan kepada umat Allah" Warta dan pesan kristiani mesti berakar dalam kebudayaan - kebudayaan 
dan untuk itu penyampaian pesan tersebut mesti sanggup tidak hanya memberi kepada melainkan juga menerima dari kebudayaan -kebudayaan yang mendengarkan Injil. Pada Sinode tersebut P. Arrupe, pemimpin Serikat Yesus berbicata tentang katekese dan inkulturasi. Inkulturasi terjadi jika hidup beriman digerakkan sungguh-sungguh oleh Roh Kudus menjadi pelayan Injil. Yesus Kristus adalah Juru Selamat bagi semua orang dengan semua kebudayaan mereka (Banawiratma, 1986). Inkulturasi mencakup proses transformasi budaya yang didorong, diarahkan, dan dijiwai oleh Injil. Pandangan para Bapa Konsili Vatikan II yang berkata bahwa kebudayaan itu "segala sarana dan upaya manusia untuk menyempurnakan dan mengembangkan pelbagai bakat pembawaan jiwa raganya" (Gaudium es Spes 53) (Martasudjita, 2005).

Perancangan interior merupakan bagian yang berintegrasi dengan struktur yang didalamnya termasuk struktur bangunan. Perbedaan mendasar antara tata ruang dalam dan luar adalah pada penggunaan atap/plafon. Tujuan desain interior adalah memperbaiki fungsi, memperkaya nilai estetika, meningkatkan aspek psikologis dari sebuah ruangan (Wicaksono \& Tisnawati, 2014).

\section{Rumusan Masalah}

Gereja HKTY Ganjuran merupakan salah satu gereja inkulturasi dengan budaya Jawa, dari segi bentuk bangunan, elemen utama interior maupun elemen pendukung interiornya. Dengan demikian makna elemen pendukung interior gereja ini menjadi salah satu hal yang menarik diteliti. Analisa elemen pendukung interior mempunyai rumusan bagaimana makna elemen pendukung interior pada arsitektur gereja Katolik Inkulturatif pada gereja HKTY Ganjuran Bantul.

\section{METODE PENELITIAN}

Penelitian ini menggunakan metode kualitatif dengan pendekatan studi kasus sehingga dapat secara mendalam dan mendetail mendapatkan data primer maupun sekunder dengan cara wawancara, dokumentasi, observasi dan studi pustaka. Peneliti wawancara langsung kepada informan sebagai sumber informasi yang berkaitan dengan hal yang diteliti. Teknik analisis datanya berupa merangkum data yang diperoleh, menjelaskan dan menyimpulkan, kegiatan ini berlangsung kontinyu sehingga data yang diperoleh sudah jenuh dan tuntas. Obyek yang menjadi penelitian adalah Gereja Hati Kudus Tuhan Yesus Ganjuran Bantul. Dengan fokus pada elemen pendukung interior berupa: furnitur (mimbar sabda, altar, kursi imam, meja kredens, kursi misdinar dan prodiakon, bangku umat), patung-patung, ragam hias diatas tabernakel, kubah diatas altar dan lukisan kaca di sebelah timur panti imam.

\section{HASIL DAN PEMBAHASAN}

Berdasarkan hasil dari wawancara, dokumentasi, observasi, studi pustaka, terdapat beberapa elemen pendukung interior. Elemen pertama yaitu perabot/furnitur dalam gereja terbagi dua bagian yakni area panti imam dan panti umat. Pada area panti imam ada tiga furniture yang wajib yaitu kursi sedilia, mimbar sabda dan meja altar. Sedang area panti umat yaitu bangku/kursi umat yang disusun menghadap ke altar. Kursi sedilia melambangkan imam sebagai pemimpin, sedang mimbar melambangkan imam sabda sebagai nabi untuk tempat pewarta. Altar menjadi pusat perhatian umat yang berkumpul, karena diatas altar, kurban salib dihadirkan. Salib sebagai simbol orang Kristen. Altar di gereja Ganjuran mengalami perubahan panjangnya karena awalnya terlalu pendek, maka terlihat ada bagian altar yang ditambahkan di samping kanan dan kiri meja altar lama. 

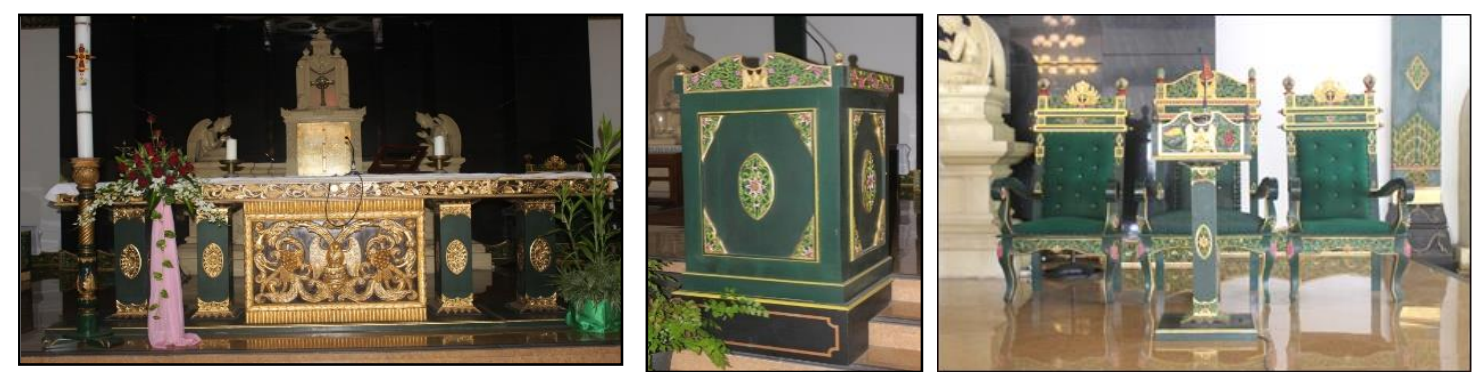

Gambar 1. Meja Altar, Mimbar Sabda, Kursi Sedilia

Sumber : Dokumentasi Pribadi, 2020

Kursi prodiakon dan misdinar terletak di samping kanan -kiri panti imam, bangku umat ditata memanjang dengan menghadap altar, agar umat terarah mengikuti ekaristi. Meja kredens berfungsi untuk meletakkan piala, patena, sibori, anggur dan air, serta untuk mendukung keperluan misa

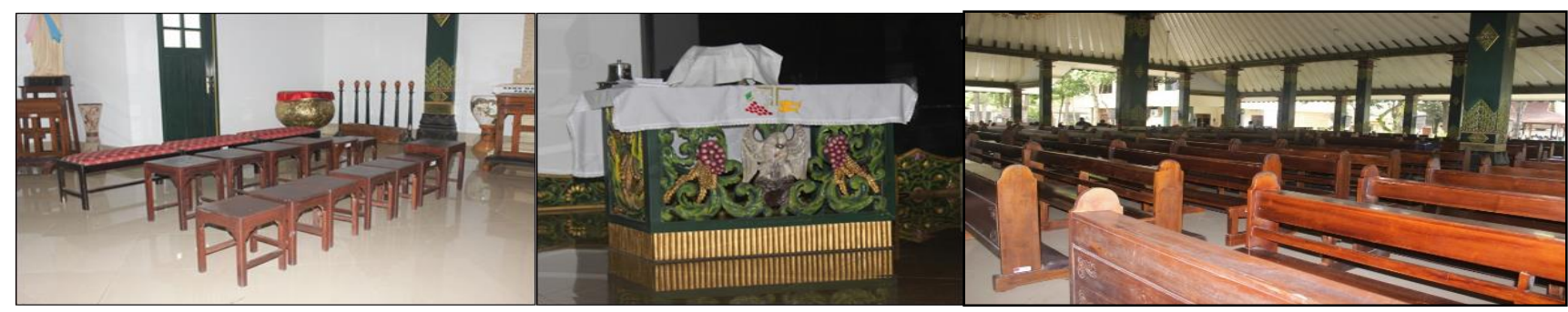

Gambar 2. Kursi Prodiakon, Meja Kredens, Bangku Umat Sumber: Dokumentasi Pribadi, 2020

Elemen kedua yaitu patung - patung dan tabernakel (ruang untuk menyimpan Sakramen Maha Kudus) yang terdapat di area panti imam, tabernakel berada di belakang altar, dan patung Yesus di sebelah barat tabernakel, dan patung Ibu Maria yang memangku Yesus berada di sebelah timur tabernakel. Patung - patung dan tabernakel tersebut merupakan peninggalan dari gereja Ganjuran yang rusak karena peristiwa gempa pada 27 Mei tahun 2006. Benda itu masih asli bersamaan dengan gereja yang diresmikan pada 16 April 1924. Patung Yesus dan Maria menggunakan busana Jawa, dengan mahkota dan asesorisnya. Harapannya umat akan lebih terarah dalam berdoa dan mengikuti misa karena Tuhan hadir dengan wajah budaya Jawa.

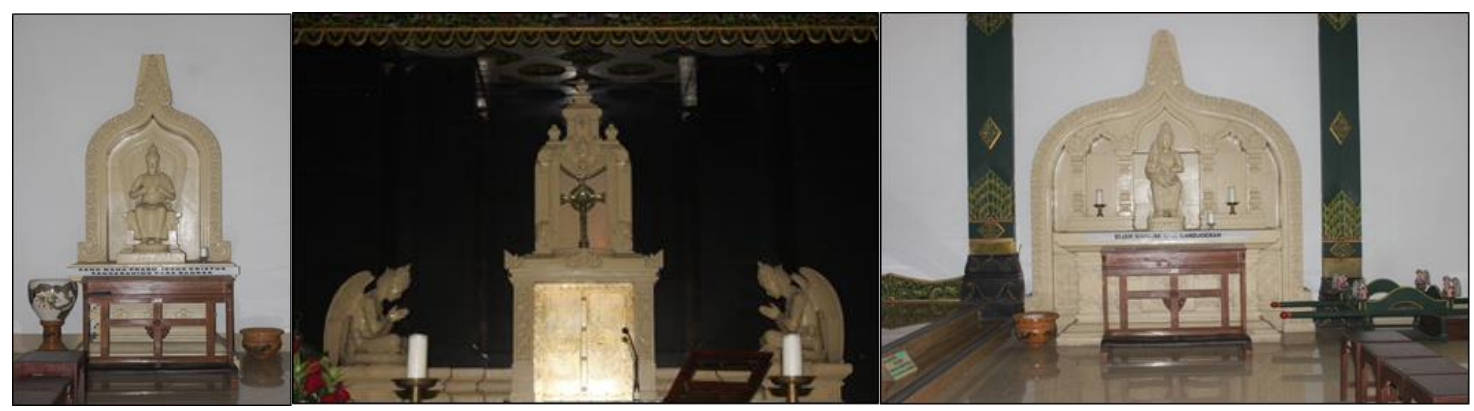

Gambar 3. Patung Yesus, Tabernakel, Patung Ibu Maria

Sumber: Dokumentasi Pribadi, 2020 


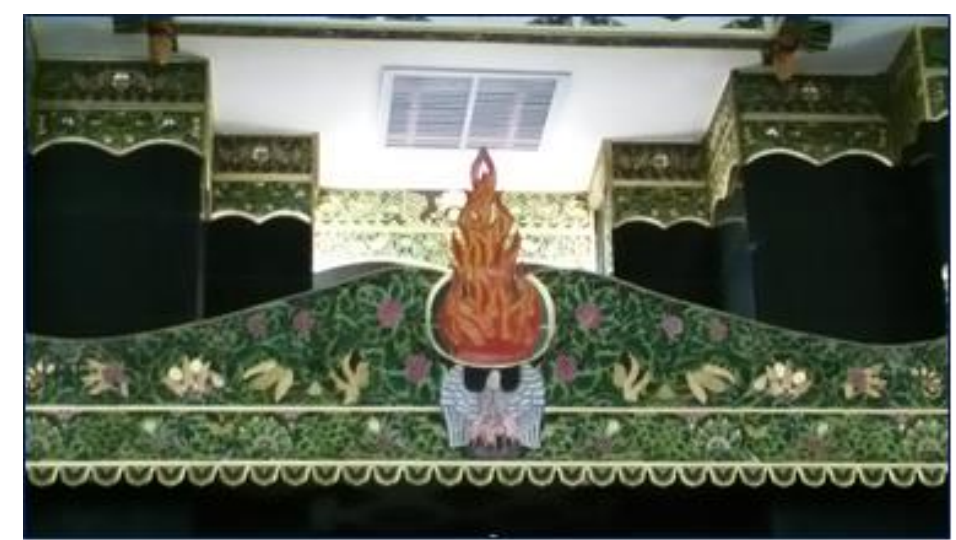

Gambar4. Ragam Hias Di Atas Tabernakel

Sumber : Dokumentasi Pribadi, 2020

Elemen ketiga yaitu ragam hias yang terdapat diatas tabernakel yaitu lidah api yang menyala nyala melambangkan Roh Kudus, dengan warna merah identik dengan semangat untuk berkorban dan kemartiran. Flora atau sulur -sulur yang berbuah anggur mengingatkan agar umat dipanggil untuk berbuat kebaikan.

Warna -warna yang dipergunakan didominasi warna hijau karena dalam gereja Katolik warna hijau di pergunakan dalam masa biasa. Dalam masa biasa penggunaan liturgi gereja dan busana dengan corak warna juga digunakan oleh imam, prodiakon, misidinar. Makna warna hijau mempunyai arti kesuburan, pertumbuhan, dan menandakan adanya kehidupan. Warna kuning emas melambangkan sebagai sumber sukacita, sumber kemuliaan. Warna kuning emas atau warna putih dipergunakan dalam masa liturgi Paskah dan Natal, pakaian yang di pakai oleh imam, prodiakon, misidinar bercorak kuning emas atau putih. Warna putih sama dengan warna kuning emas melambangkan meraih kemuliaan Tuhan Yesus dimulai setiap hari dengan aneka kehidupan. Warna hitam melambangkan kesejatihan, asal mula. Pada beberapa perabot (altar, meja kredens, kursi sedilia, mimbar sabda, hiasan diatas tabernakel) terdapat ukiran burung pelican dengan anaknya berjumlah tiga. Legenda pelican ini menampakkan Hati Kudus Yang Maha Kudus. Ada kisah yang menjadi latar belakangnya yaitu pada saat di Eropa mengalami masa paceklik yang panjang induk burung pelikan itu melukai tubuhnya dan memberikan darahnya keluar dan menjadi makanan bagi anak-anaknya hingga musim kekeringan itu berlalu yang akhirnya induk burung pelikan tersebut mati. Induk burung pelikan yang berwarna putih memberikan darahnya pada anak-anaknya yang berwarna merah muda. Warna putih mempunyai arti kesucian. Warna merah muda melambangkan tanda - tanda adanya kehidupan.

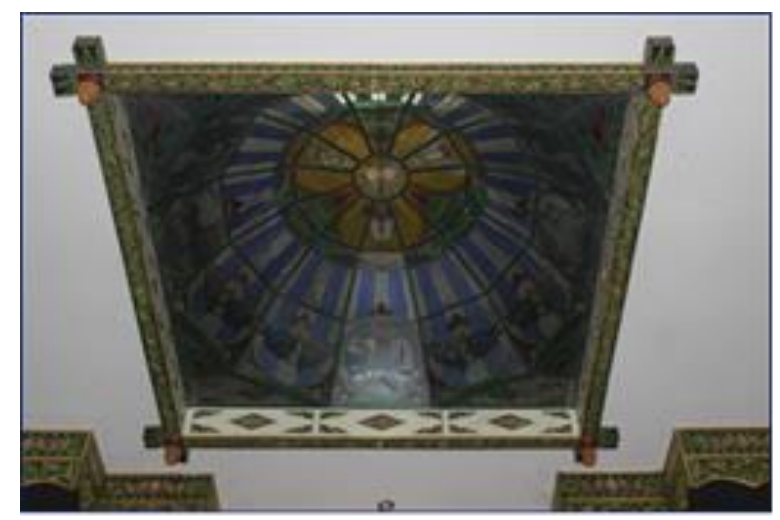

Gambar 5. Kubah Diatas Altar

Sumber : Dokumentasi Pribadi, 2020 
Elemen keempat adalah kubah yang berada di atas altar terdapat gambar ke empat Injil suci yaitu Injil Matius yang dilambangkan dengan manusia bersayap karena perannya sebagai penginjil, Injil Markus dilambangkan dengan seekor singa yang bersayap, Injil Lukas dilambangkan dengan seekor lembu, Injil Yohanes dilambangkan dengan seekor rajawali. Serta gambar Tritunggal Maha Kudus yang sama dengan lukisan/gambar di dalam Candi HKTY Ganjuran. Maksud pembuatan kubah ini adalah ketika Imam melakukan konsekrasi dan menengadah keatas untuk selalu meresapi keempat injil dan Tritunggal Maha Kudus.

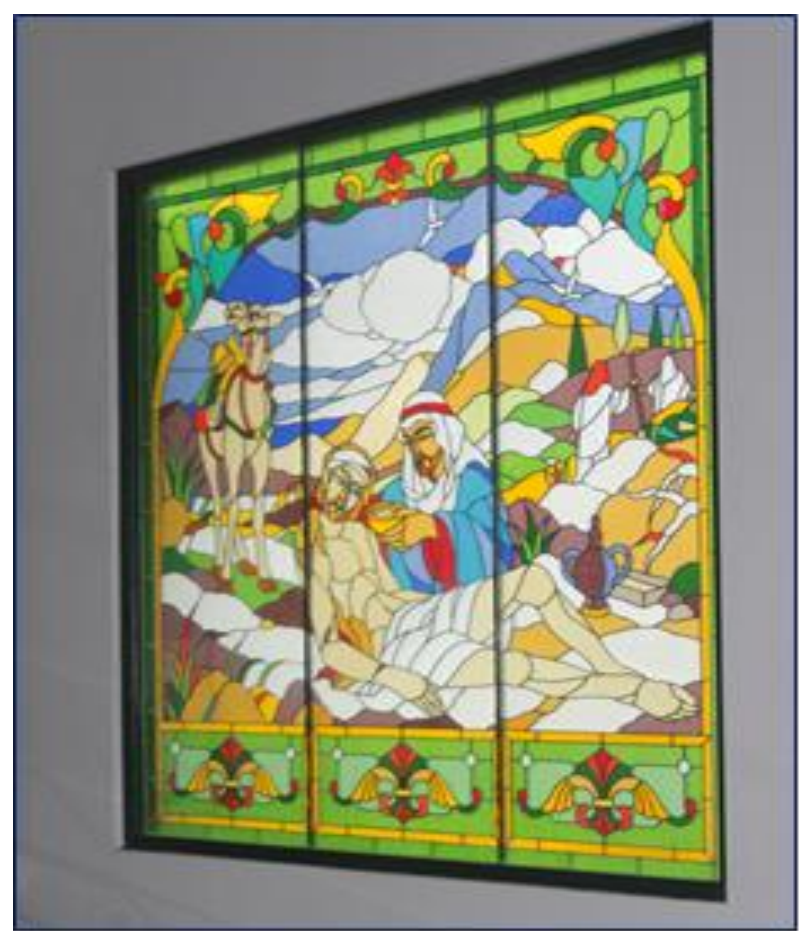

Gambar 6. Lukisan Kaca Orang Samaria

Sumber: Dokumentasi Pribadi, 2020

Elemen kelima adalah lukisan kaca tentang orang Samaria yang baik hati ini terletak di sisi timur panti imam gereja Ganjuran. Lukisan ini sengaja di pasang di sisi timur agar terkena sinar matahari saat terang, sehingga keindahannya nampak jelas dan menarik perhatian umat yang hadir di gereja. Melalui kisah orang Samaria ini, diharapkan umat Katolik seusai mengikuti perayaan ekaristi siap sedia berbuat bagi siapapun yang membutuhkan, sebab iman tanpa perbuatan adalah mati.

Selaras dengan penelitian, (Pinasthika, 2011) bahwa gereja Ganjuran secara keseluruhan lebih kuat aspek budaya Jawa, namun aspek tersebut cenderung dekoratif sehingga tidak mengubah ajaran Katolik. Penggambaran yang banyak beradaptasi dengan budaya Jawa adalah patung Yesus dan Maria serta malaikat pada tabernakel. Didalam gereja terdapat ukiran yang didominasi tumbuhan secara simbolis mempunyai arti kehidupan, ukiran anggur dan tangkai mengandung arti Tubuh dan Darah Kristus, ukiran burung merpati dan lidah api melambangkan Roh Kudus. Salib serta lilin bermakna simbolis pengorbanan Yesus yang wafat di kayu salib, (Kurnianto, 2016). Menurut (Cahyo Nugroho, 2016) secara estetika gereja Ganjuran memiliki ciri khas yaitu arsitektur kejawaannya yang kuat. Inkulturasi antara budaya Jawa dengan agama Katolik yang terwujud dalam ornamen-ornamen gereja. Perpaduan tersebut nampak pada patung-patung Yesus dan Maria serta malaikat dalam panti imam. 
Berdasarkan hasil penelitian yang diolah dari wawancara, observasi, studi dokumentasi maka makna elemen pendukung interior tersebut mempunyai makna secara liturgis dan mendukung umat untuk berdoa dan beribadat, sebagai sarana untuk umat belajar tentang agama Katolik. Inkulturasi dalam agama Katolik semakin lengkap dengan adanya gereja yang mempunyai arsitektur dan interior sesuai dengan budaya setempat dalam hal ini di Gereja HKTY Ganjuran berupa budaya Jawa.

\section{KESIMPULAN}

Elemen pendukung interior berupa furnitur, patung-patung, ornamen hias, kubah diatas tabernakel, lukisan kaca mempunyai makna yang mendukung umat untuk beribadat kepada Tuhan. Terlebih dengan penggunaan ragam hias dan warna - warna yang mepunyai arti secara liturgis.

Umat ketika berdoa atau mengikuti misa semakin terarah kepada Tuhan karena didukung oleh interior gereja yang mendukung sarana untuk beribadah. Dampaknya umat semakin fokus karena Tuhan Yesus hadir dalam wajah budaya setempat.

Harapannya penelitian ini menjadi bagian penting bagi desainer atau arsitek untuk merancang gereja mengambil tema sesuai dengan budaya setempat. Arsitektur maupun interior gereja inkulturatif semakin tumbuh dan mempunyai dampak bagi pertumbuhan iman umat.

\section{Ucapan Terima Kasih}

Terima kasih kami sampaikan kepada, Para Pastur Gereja HKTY, Rm. Herman Yosep Singgih Sutoro, Pr, Rm. Y. Krismanto, Pr, Sekretariat Paroki HKTY, dan, segenap informan lainnya. Terima kasih pada PAPKI, selaku institusi sponsor, Direktur PIKA, Direktur ATPIKA.

\section{REFERENSI}

Banawiratma, J. B. (1986). Kajian Kristologis Allah Tri Tunggal. Yogyakarta: Kanisius.

Bramasti, D. (2015). Dampak Sosial Sebuah Karya Seni Pada Kaum Miskin Dan Tertindas Kajian Sosiologis Pada Candi Ganjuran. Patrawidya, 16, 429-446.

Cahyo Nugroho, B. A. (2016). Karakteristik Kejawaan Arsitektur Gereja Katolik Ganjuran (Tahun 1924-2013). Yogyakarta: Universitas Sanata Dharma.

Kurnianto, Y. A. (2016). Makna Simbolis Dekorasi Di Komplek Gereja Ganjuran Kabupaten Bantul Daerah Istimewa Yogyakarta. Yogyakarta: Universitas Negeri Yogyakarta.

Martasudjita, E. (2005). Inkulturasi Gereja Katolik Di Indonesia. Studia Philosophica et Theologica, Vol.5, No.2, 127.

Pinasthika, R. (2011). Tinjauan Inkulturasi Budaya Jawa Pada Ornamen Hias Dalam Interior Gereja Katolik Ganjuran. Jurnal Tingkat Sarjana Bidang Seni Rupa dan Desain No 1, ITB Bandung.

Sitinjak, R. H. (2011). Arsitektur Dan Interior Gereja Inkulturatif Pangururan: Pemaknaan dengan Metode Hermeneutik Ricoeur. Yogyakarta: ISI Yogyakarta.

Wicaksono, A., \& Tisnawati, E. (2014). Teori Interior. Jakarta: Griya Kreasi. 
Makna Elemen Pendukung Interior Pada

Robertus Krismanto, et. al.

Arsitektur Rumah Ibadah 